\title{
Peningkatan Pengetahuan Enterpreneur Dengan Financial Technology (Fintech) Untuk Generasi Milenial Di Karang Taruna Trimanunggal Bibis Luhur Kota Surakarta
}

\author{
Tri Nurdyastuti ${ }^{1}$, Yofhi Septian Panglipurningrum ${ }^{2}$, Suroto $^{3}$, Dibyo Iskandar ${ }^{4}$ \\ ${ }^{1,4}$ Program Studi Akuntansi, ${ }^{2}$ Manajemen ${ }^{3}$ Manajemen Informatika, \\ ${ }^{1,2,3}$ STIE Adi Unggul Bhirawa Surakarta \\ e-mail: tri.nurdyastuti@stie-aub.ac.id ${ }^{1}$,yofhi.septian@stie-aub.ac.id ${ }^{2}$, suroto@stie-aub.ac.id
}

\begin{abstract}
Abstrak
Pertumbuhan generasi milenial Indonesia menjadi sebuah kekuatan untuk membentuk masyarakat Indonesia menjadi lebih maju, mulai dari kemajuan ekonomi, teknologi, E-commerce dan berbagai bidang lainnya. Peranan generasi milenial saat ini sangat besar untuk membangun bangsa, cara berpikir generasi milenial yang luas dapat membuat perubahan dan dapat menjadi pelopor bukan hanya sekadar mengikuti tren yang sudah ada, akan tetapi dapat menciptakan hal-hal yang baru di masyarakat. Untuk bisa melahirkan wirausaha-wirausaha muda bukan sesuatu hal yang mudah, karena bukan hanya masalah ketersediaan modal, teknologi, pasar dan kreativitas untuk bisa menjadi wirausaha, tetapi mental, sikap dan perilaku wirausaha yang kuat harus tertanam secara mendalam agar bisa menjadi wirausaha yang tangguh. Tim pengabdian kepada masyarakat telah melaksanakan kegiatan pengabdian dengan judul "Pelatihan dan Pendampingan Penigkatan Jiwa Enterpreneur dengan Financial Technology (Fintech) Di Era Milenia Bagi Karang Taruna Trimanunggal Bibis Luhur Surakarta". Kegiatan pengabdian ini berupa ceramah tentang pentingnya fintec dalam berwirausaha.
\end{abstract}

Kata Kunci: Fintech, Enterpreneur , generasi milenial

\section{PENDAHULUAN}

Era globalisasi dapat meningkatkan kehidupan ekonomi Indonesia menjadi lebih baik, namun datangnya era globalisasi pada bidang ekonomi merupakan tantangan masyarakat Indonesia khususnya para generasi milenial yang harus mempersiapkan diri dalam menghadapi persaingan global saat ini, perkembangan teknologi dan komunikasi di era digital saat ini membuat bisnis di Indonesia memiliki kemajuan dalam hal persaingan pasar global. Generasi milenial mempunyai pemikiran yang lebih inovatif, kreatif dan kritis, Pertumbuhan generasi milenial Indonesia menjadi sebuah kekuatan untuk membentuk masyarakat Indonesia menjadi lebih maju, mulai dari kemajuan ekonomi, teknologi, $E$ commerce dan berbagai bidang lainnya. (Student's Column, 2019)

Keuntungan lain dalam berwirausaha di usia muda adalah begitu dekat dengan teknologi terkini. Perkembangan teknologi yang kian pesat seperti sekarang ini, membuat para pelaku wirausaha dapat mendapatkan kemudahan dari segi akses internet sebagai media pemasaran, promosi, atau berbisnis. Bahkan, wirausaha dengan memanfaatkan bisnis daring semakin jamak dilakukan, seperti membuka toko daring, menjual jasa SEO (search engine optimization) dan SEM (search engine marketing), freelance writer, dan masih banyak lagi. Di usia yang relatif muda, tentunya dapat memahami selera pasar seusia. Milenial dengan baik mengenal selera anak muda, serta memahami apa yang sedang menjadi tren, atau yang akan menjadi trendsetter. Jadi, tidak perlu menunggu cukup umur untuk membangun bisnis baru bila milenial mampu menjadi wirausaha sukses. (Life Changer Allianz, 2018)

Peranan generasi milenial saat ini sangat besar untuk membangun bangsa, cara berpikir generasi milenial yang luas dapat membuat perubahan dan dapat menjadi pelopor bukan hanya sekadar mengikuti tren yang sudah ada, akan tetapi dapat menciptakan hal-hal yang baru di masyarakat. Untuk bisa melahirkan wirausaha-wirausaha muda bukan sesuatu hal yang mudah, karena bukan hanya masalah ketersediaan modal, teknologi, pasar dan kreativitas untuk bisa menjadi wirausaha, tetapi mental, sikap dan perilaku wirausaha yang kuat harus tertanam secara mendalam agar bisa menjadi wirausaha yang tangguh. Hal ini bukan sesuatu hal yang mudah dan dapat diciptakan dalam waktu singkat,tetapi harus ditanam dan dipahami secara lebih dini sejak usia sekolah, sehingga pada saat meninggalkan bangku kuliah seseorang telah berani menyatakan dirinya untuk berwiraswasta. (Kusumaningsih dkk., 2018). Kegiatan pengabdian Membangun Jiwa Enterpreneur dengan Financial Technology (Fintech) Di Era Milenia Bagi Karang taruna Tri Manunggal Bibis Luhur Surakarta ini terencana dari identifikasi masalah terkait data penduduk angkatan kerja (PAK) 2018 Kota Surakarta menunjukkan angka pengangguran 
mencapai 12 ribu jiwa dari total penduduk 520 ribu jiwa di dominasi lulusan pendidikan tinggi (Jawa Pos.com, 2019). Penguasaan ilmu Kewirausahaan dan teknologi melalui kegiatan PKM (Pengabdian Kepada Masyarakat) secara khusus adalah salah satu ujung tombak dalam pengembangan, dan pemanfaatan yang dapat mengubah, memperbaiki serta meningkatkan kulitas sumber daya manusia.

Tim pengabdian mengajukan tema Enterpreneur dengan fintetech agar dapat mengatasi permasalahan tersebut. Tim pengabdian melakukan pendekatan kepada remaja generasi milenia untuk memotivasi menjadi wirausaha-wirausaha muda melalui kegiatan pengabdian dengan judul "Pelatihan dan Pendampingan Penigkatan Jiwa Enterpreneur dengan Financial Technology (Fintech) Di Era Milenia Bagi Karang Taruna Trimanunggal Bibis Luhur Surakarta"

\section{METODE PENGABDIAN}

Kegiatan Pengabdian Kepada ini berbentuk ceramah dan diskusi secara online kepada generasi milenia anggota karang taruna Tri Manunggal melalui media Zoom dengan tujuan memberikan edukasi akan pentingnya fintech dalam meningkatkan Jiwa Enterpreneur di era milenia bagi karang taruna Trimanunggal Bibis Luhur Surakarta". Sebelum memutuskan tema kegiatan tim PKM melakukan penyebaran kuisioner tentang kebutuhan akan materi para peserta. Materi yang disampaikan dalam kegiatan PKM tersebut antara lain penjelasan tentang fintech dan pengaruhnya terhadap gaya hidup, fintech dan perkembangannya di Indonesia, serta jenis fintech dan regulasinya sehingga ada pengetahuan tentang fintech dan tumbuh keinginan untuk berwirausaha dengan memanfaatkan fintech.

Pengukuran tingkat keberhasilan kegiatan dengan uji beda (Paired sample t-test) serta kemampuan peserta dalam mempraktekkan kegiatan tersebut. Paired sample t-test adalah jenis uji statistika yang bertujuan untuk membandingkan rata-rata dua grup yang saling berpasangan. Sampel berpasangan dapat diartikan sebagai sebuah sampel dengan subjek yang sama namun mengalami 2 perlakuan atau pengukuran yang berbeda, yaitu pengukuran sebelum dan sesudah dilakukan sebuah treatment. Rancangan ini paling umum dikenal dengan rancangan pre-post, artinya membandingkan rata-rata nilai pre- test dan rata-rata post test dari satu sampel. Metode ini menggambarkan bahwa responden akan di ukur test pengetahuannya sebelum penyuluhan (nilai pre-test) dan di ukur test pengetahuannya setelah penyuluhan (nilai post test) selanjutnya nilai masingmasing responden di bandingkan antara sebelum penyuhan (pre-test) dengan setelah penyuluhan (post-test). Jadi satu sampel akan memiliki dua buah data. (Ghozali, 2013). Rumus uji beda t berpasangan adalah sebagai berikut:

$$
\begin{gathered}
t=\frac{\text { Rata-rata sampel pertama }- \text { Rata-rata sampel kedua }}{\text { Standar eror perbedaan rata-rata kedua sampe }} \\
\text { Sumber : Ghozali (2013) }
\end{gathered}
$$

\section{HASIL DAN PEMBAHASAN}

Kegiatan pengabdian masyarakat ini dilaksanakan secara oline melalui aplikasi zoom dengan Zoom Meeting ID $788 \quad 170 \quad 0951$ Passcode aubsolo atau melalui link join online https://us04web.zoom.us/j/7881700951?pwd=cUgrL1U0Z0FxcTIHSHUSHo0DNNz09.

Kegiatan Pengabdian Masyarakat ini diikuti oleh generasi milenia anggota karang taruna Tri Manunggal, Bibis Luhur, Surakarta. Peserta yang hadir berjumlah 25 orang. Kegiatan dilanjutkan dengan pemberian materi, sebelum menyampaikan materi tim pengabdian melakukan pretes terkait materi yang akan disampaikan. Materi pertama yang disampaikan terkait penjelasan tentang fintech dan pengaruhnya terhadap gaya hidup, fintech dan perkembangannya di Indonesia, serta jenis fintech dan regulasinya. 


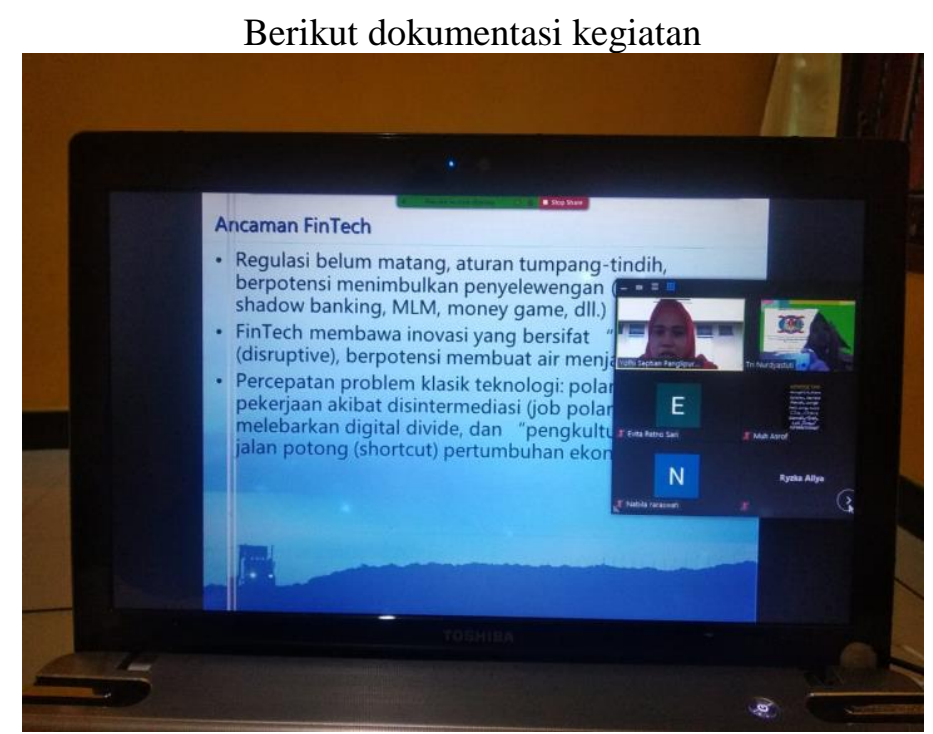

Gambar 1 Penyampaian Materi Tim PKM

Analisis dilakukan dengan menggunakan uji beda untuk mengetahui apakah terdapat perbedaan pemahaman tentang materi yang diberikan sebelum pelatihan dan sesudah pelatihan. Hasil analisis data sebagai berikut:

Tabel IV.1

Paired Samples Statistic

\begin{tabular}{|cc|c|c|c|c|}
\hline & & & & & \\
& & Mean & $\mathrm{N}$ & Std. Deviation & $\begin{array}{c}\text { Std. } \\
\text { Error }\end{array}$ \\
\hline Pair & Pretest & 58,0000 & 25 & 5,95119 & 1,19024 \\
1 & posttest & 81,8000 & 25 & 6,75154 & 1,35031 \\
\hline
\end{tabular}

Dari hasil diatas menunjukkan bahwa rata-rata pemahaman terhadap materi sebelum dan sesudah dilakukan pelatihan pada peserta. Sebelum pelatihan rata-rata pemahaman terhadap materi dari 25 orang peserta adalah sebesar 58,00 sementara setelah diberikan pelatihan rata-rata pemahaman peserta sebesar 81,80

Tabel IV.1

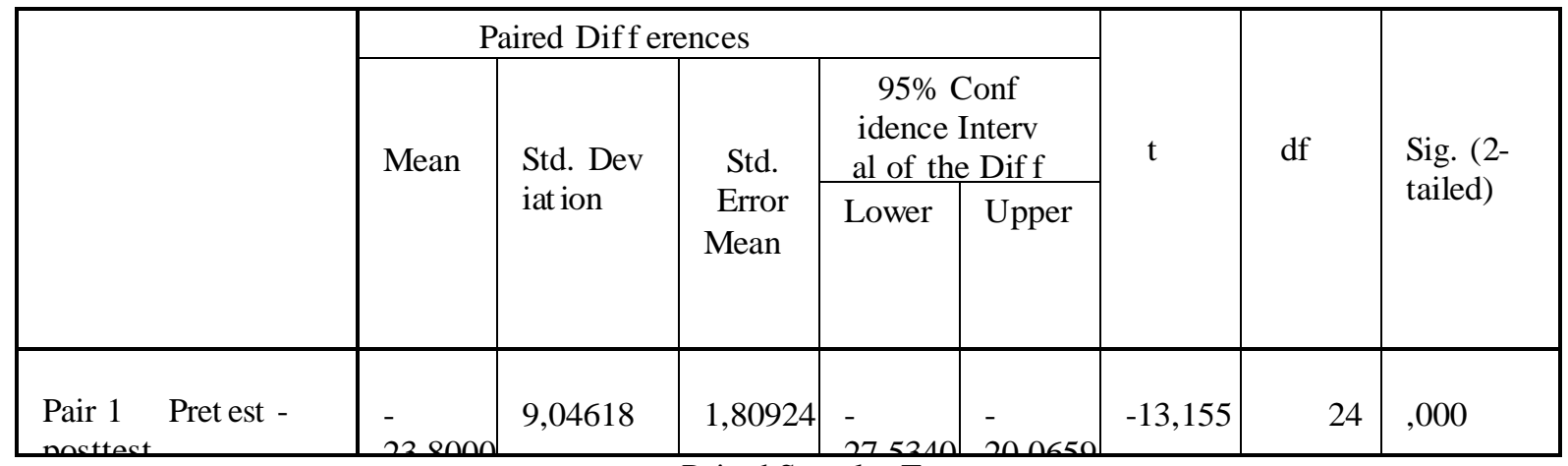

Paired Samples Test

Nilai t hitung sebesar $-13,155$ dengan sig $0.000<0.05$, artinya rata-rata pemahaman sebelum dan sesudah pelatihan dan pendampingan terhadap peserta terdapat perbedaan. Dengan demikian dapat dinyatakan bahwa penyampaian materi dan pelatihan sangat mempengaruhi pemahaman dan keterampilan peserta pelatihan dalam memanfaatkan fintech.

Apabila disajikan dalam tabel perbedaan kemampuan awal pada saat pre-test dan kemampuan 
akhir pada saat post-test disajikan dalam gambar 1 sebagai berikut :

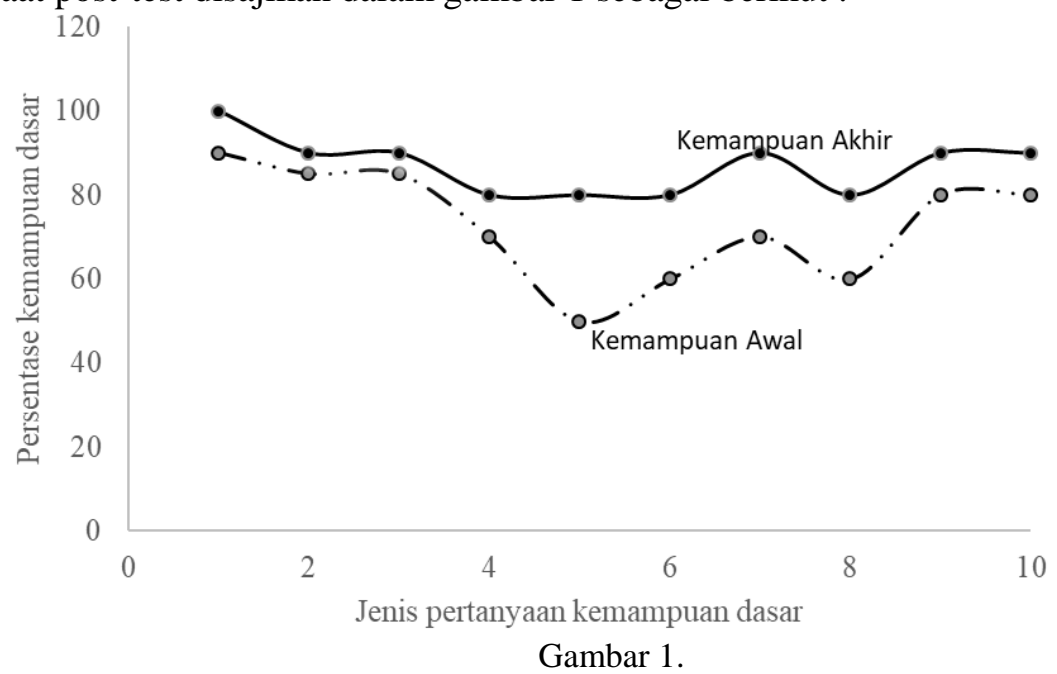

Hasil test kemampuan dasar peserta awal (pre-test) dan akhir kegiatan (post-test)

\section{SIMPULAN}

Berdasarkan hasil dan pembahasan kegiatan pengabdian kepada masyarakat dapat disimpulkan bahwa :

1. Wawasan generasi milenia karang taruna Tri Manunggal tentang pentingnya fintech dalam berwirausaha mulai tumbuh.

2. Sudah terbentuk pola pikir generasi milenia karang taruna Tri Manunggal untuk dapat memanfaatkan teknologi sebagai jembatan untuk menjadi wirausahawan.

3. Sudah ada keinginan generasi milenia karang taruna Tri Manunggal menjadi wirausahawan dengan memanfaatkan fintech.

4. Penyelenggaraan program pengabdian kepada masyarakat pentingnya fintech dalam berwirausaha generasi milenia karang taruna Tri Manunggal diharapkan kegiatan seperti ini dapat dilakukan secara berkesinambungan dan berlanjut pada strategi pemasaran dengan memanfaatkan fintech.

\section{SARAN}

Saran yang dapat diberikan tim pengabdian agar hasil pengabdian jauh lebih baik yaitu peserta diharapkan berani untuk membuka usaha dan memanfaatkan fintech dengan bekal pelatihan dan pendampingan yang telah mereka ikuti.

\section{DAFTAR PUSTAKA}

https://www.online-pajak.com/tentang-pajak-pribadi/fintech

Jawa Pos.com. (2019, Oktober). 12 Ribu Usia Produktif Nganggur. https://radarsolo.jawapos.com/read/2019/10/23/162482/12-ribu-usia-produktif-nganggur

Kusumaningsih, A., Putri, A., Supriadi, A., \& Priadi, A. (2018). Pembinaan Kewirausahaan Berbasis Fintech (Financial Technology) Untuk UMKM Di Koperasi Cipta Boga Keranggan, Tangerang Selatan. 01, 192-201.

Life Changer Allianz. (2018). Membangun Bisnis Sendiri Bukan Lagi Sebuah Mimpi. Student's Column. (2019). Era globalisasi menuntut generasi milenial berjiwa entrepreneur Life Changer Allianz. 